San Jose State University

SJSU ScholarWorks

Faculty Publications

Health Science and Recreation

5-1-2012

\title{
Iraq and Afghanistan veterans' experiences living with their parents after separation from the military
}

Miranda E. Worthen

San Jose State University, miranda.worthen@sjsu.edu

M Moos

Stanford University

R Ahem

University of California - Berkeley

Follow this and additional works at: https://scholarworks.sjsu.edu/healthsci_rec_pub

Part of the Medicine and Health Sciences Commons

\section{Recommended Citation}

Miranda E. Worthen, M Moos, and R Ahem. "Iraq and Afghanistan veterans' experiences living with their parents after separation from the military" Contemporary Family Therapy (2012): 362-375. https://doi.org/ 10.1007/s10591-012-9196-4

This Article is brought to you for free and open access by the Health Science and Recreation at SJSU

ScholarWorks. It has been accepted for inclusion in Faculty Publications by an authorized administrator of SJSU

ScholarWorks. For more information, please contact scholarworks@sjsu.edu. 
Afghanistan and Iraq war veterans' experiences living with their parents after separation from the military

Worthen, M., Moos, R., Ahern, J.

\begin{abstract}
When military service members separate from the military, many return to their families of origin, living with their parents for a period of several weeks to years. While research with veterans and their spouses has documented the particular strain of this reintegration period on veterans and their partners, little research to date has examined veterans' experiences living with their parents. The present study sought to fill this research gap by investigating veterans' experiences living with their parents using qualitative, in-depth interviews with Iraq and Afghanistan veterans in California. Overall, veterans appreciated the instrumental and emotional support their parents provided when they separated. However, in some cases, living with parents also produced conflict and strain. In situations where adult veteran children had difficulty with the transition to civilian life or returned with mental health problems, parents were often the first to identify these problems and to support their children in accessing appropriate care. We analyze these findings in light of family systems theory, identifying ways in which adult veteran children continue a process of differentiation while living with their parents and maintaining emotional connectedness. We suggest ways that clinicians can better support veterans and their parents through the reintegration period and recommend that programming for military families explicitly include parents of service members in addition to conjugal families.
\end{abstract}

\title{
KEYWORDS
}

Military, Veterans, Parents, Family Systems Theory, Reintegration

\section{INTRODUCTION}

Since September 11, 2001, over 1.9 million men and women have been deployed in support of the wars in Afghanistan and Iraq; more than a million of these service members have now separated from the military (Institute of Medicine 
2010; Karney et al. 2008; Tanielian and Jaycox 2008). When service members separate from the military, many return to live with their parents. For example, $27 \%$ of young veterans (less than 30 years of age) in California currently live with their parents, and a larger proportion of veterans live with their parents for some period of time after separation (CHIS 2011). Among unmarried young veterans, nearly half (49\%) currently live with their parents (CHIS 2011).

Extensive research has examined how reintegration into the family affects veterans, their spouses, and their children. Current era veterans and their spouses struggle with redefining family roles and division of household labor, renewing intimacy, and creating a shared understanding of the meaning of the deployment experience (Bowling and Sherman 2008; Faber et al. 2008; Sayer et al. 2009). While veterans and spouses may struggle to adjust to one another after long separation and changes that occur during war (Hollingsworth 2011; Hutchinson and Banks-Williams 2006; Makin-Byrd et al. 2011), many couples show resilience in adapting to a "new normal" (Lapp et al. 2010; Tanielian and Jaycox 2008). When a veteran returns with posttraumatic stress disorder (PTSD), couples experience high levels of marital distress and spouses suffer increased psychological morbidity (Hayes et al. 2010; Renshaw et al. 2008). Children of veterans report difficulties reconnecting with the veteran parent, and often experience high levels of anxiety and difficulties at school (Chandra et al. 2008; Lester et al. 2010). Further, children experience an elevated burden of mental health diagnoses both during and after parental deployments (Chandra et al. 2008; Mansfield et al. 2011; McFarlane 2009).

Only one study to date has addressed parents' experiences during the deployment of their adult children (Crow and Myers-Bowman 2011). This research found that parents have a mix of emotions, most marked by fear for their children's safety and pride in their service. Two qualitative studies have explored the experiences of family other than spouses as military service members return home from deployment (Demers 2009; Faber et al. 2008). Each of these studies reported that parents and adult veteran children struggled to redefine family roles after the service members returned home (Faber et al. 2008; Demers 2009). To our knowledge there has been no research on experiences of veterans who live with their parents after separation from the military. Given how common it is for veterans to live with their parents after separation from the military, there is a 
need to understand this experience. By clarifying how veterans experience this transition, families can be better prepared to welcome veterans home, potentially reducing distress, anxiety, and psychological symptoms often experienced by members of the household.

\section{THEORETICAL FRAMEWORK}

Family systems theory (Bowen 1966, 1974) envisions individuals as part of a dynamic family system changing through time. The family system reacts to relationships in the past, present, and anticipated future (Carter and McGoldrick 2005b). There are emotional tasks for family members at each stage in the family life cycle; these tasks take place within a context of stressors that occur at individual, immediate family, extended family, community, and societal levels (Carter and McGoldrick 2005b; Skowron et al. 2009). Potential stressors are developmental (e.g. life cycle transitions), unpredictable (e.g. illness or unemployment), or historical (e.g. war or economic depression). Families often experience the most distress during the transition from one life cycle stage to the next. When these developmental transitions occur within a context of unpredictable or historical stressors, added anxiety impacts the family system, increasing the potential for psychological distress or conflict in the family.

A critical theoretical construct within family systems theory is "differentiation of the self" as an individual reaches emotional maturity. In contrast with "separation," differentiation is about becoming autonomous while recognizing one's relational interdependence and remaining connected to sources of emotional support (Rosen 2005, Sahin et al. 2010). Healthy psychological development occurs when individuals are able to "rebalance, redefine, and realign" relationships within the family system in response to life cycle changes (Carter and McGoldrick 2005b, 2005a). Greater differentiation of the self is associated with improved psychological and interpersonal well-being (Skowron et al. 2009). According to family systems theory, young adults who return home after living apart from their parents can pursue a normal pathway towards differentiation (Blacker 2005). Living at home can be a "convenient, temporary, and orderly way to prepare for adulthood" (Fulmer 2005).

\section{METHODS}




\section{Recruitment}

The present study uses a subset of the data collected as part of a broader study of veterans' reintegration. For the larger study, we conducted in-depth interviews with 24 Afghanistan and Iraq war veterans in 2009-2011 in California. Veterans were recruited purposively to include both women and men and a range of ages, race/ethnicities, and military service branches. We contacted veteran service providers, representatives of the veteran community, and veteran clubs to advertize the study via email, flyers, and postings on social networking sites. These posts described the study and invited Afghanistan and Iraq war veterans to contact the study director. Interested participants were screened for eligibility and invited to complete the interview in person or by phone. Participants completing in person interviews read a written description of the study and gave written informed consent prior to the start of the interview. Participants electing to complete the interview by phone were read a description of the study and gave oral consent. These participants were offered an email copy of the informed consent document. Study procedures were reviewed and approved by the Committee for the Protection of Human Subjects at the University of California, Berkeley.

Interviews

Interviews were semi-structured, using an open-ended interview guide. Interviews focused on the veterans' experiences after separation, including what made things easier or more difficult. Veterans were asked to describe their reintegration experiences within specific social domains, including family, friends, and work or school. Here, we specifically consider the parts of the interviews that focused on the family. The Study Director (MW), who has extensive experience conducting qualitative interviews with former combatants, conducted all interviews. Interviews lasted an average of 60 minutes and were audiotaped and transcribed for analysis.

\section{Analysis}

We used a multi-stage analytic process that combined inductive and deductive techniques to analyze the transcribed interview data. First, we developed an initial codebook based on theories of social environments (Berkman and Glass 2000; 
Bronfenbrenner 1979; House 1981) and on reading a small number of transcripts. For example, initial codes included the social environments of family, friends, veterans, and community/neighborhood. We included codes for important aspects of these environments, such as social support, norms and values. Inductive processes were used to enrich the codebook with emergent themes. For example, structure was added as an aspect of social environments. We used a coding process where text was coded with multiple codes (e.g. a single quote could be coded with the terms "family," "structure," "readjustment," and "support"), and elected to code larger sections of text in order to provide context for quotations (Sheon 2007).

Three group members independently coded four transcripts based on an initial codebook, and then met to discuss coding decisions, reconcile discrepancies, and revise the codebook. Subsequently, these three group members coded two transcripts using the revised codebook; remaining minor discrepancies were discussed and reconciled. The Study Director (MW) then coded all transcripts using the qualitative software program atlas.ti (atlas.ti 2011). After coding was complete, the authors read code reports to extract central themes, explore meanings, and examine relationships among themes within the data. The present analysis uses all data codes relevant to the family.

\section{Participants}

The 24 veteran participants reported a range of living situations upon separation. Of those 25 years old or younger, 8 of $11(73 \%)$ lived with their parents when they separated, and of those $26-31$ years old 3 of 8 (37.5\%) lived with parents. Three of the $5(60 \%)$ veterans over the age of 31 lived with their spouse upon separation, while one veteran lived with extended family and another lived alone. See Table 1 for a summary of participant living situations. This article focuses on the experiences of the 11 respondents who lived with their parents after separation.

Veterans who lived with their parents ranged from 22 to 34 years of age; time since separation from the military ranged from 2 months to 5 years. Veterans had been associated with all branches of the armed services and were racially and ethnically diverse. Of the 11 veterans, 9 were men and 2 were women. See Table 2 for a detailed description of the sample. 


\section{RESULTS}

Veterans spoke at length about their experiences living with their parents. In this section, we present veterans' perceptions of the instrumental (tangible assistance) and emotional support their parents provided and a description of some of the difficulties veterans reported in redefining family roles. We also present veterans' descriptions of how their families responded to their difficulties with readjusting to civilian life and the experiences reported by two women veterans who lived with their parents after being sexually assaulted during their military service. We analyze these findings in light of family systems theory.

Parents provide instrumental support

Veterans appreciated the support of having a place to live immediately after separation. One veteran described the situation this way: "After I got out I lived with my parents for a little bit. I was self-supportive, but I lived with them just until I found something that was decent-paying ... [So I could] go on my own, because you're going from having someone support you with housing [and to]... jump into an apartment was kind of difficult. So... I lived with my parents for about a year."

While some veterans lived with their parents for a single period of time, others used their parents' home as a base from which to try different pursuits after return. One veteran described how he lived with his parents for two months before starting school in a different part of the state. When he dropped out of that school, he lived with his parents again for five months until he found a job. Consistent with family systems theory, which posits that differentiation can continue while young adults reside with their parents (Bowen 1966; Carter and McGoldrick 2005b), these veterans used their parents' instrumental support to help them pursue independence. By taking the time to find suitable employment, veterans were more likely to be self-supporting when they left their parents' home.

As expected, younger, unmarried veterans were more likely to live at home with their parents than married veterans. However, one participant described how he lived in his parents' home with his adult siblings, his wife, and his two young children: "It's the first time the family's been together in seven years and they have grandkids now... I know a lot of people think... 'Oh, it must 
be horrible.' But my family's pretty tight. [Living together is] actually considered a good thing.

Parents provide emotional support but may lack understanding In addition to the instrumental support living in parents' homes provided, for several veterans, living together with parents created a space for parents to provide emotional support during the transition to civilian life. Many veterans spoke of the pleasure of reconnecting after the long separation due to military service: "For the past month, I've just been spending time with family.... Really enjoying having them around for a change." Another reported, "We caught up for some of the years that we weren't around each other."

Several veterans discussed the emotional support their parents provided. One veteran said: "They try to help me in every way, they always ask me what I'm thinking. When I first got here, am I comfortable with this. Or do I feel weird being here? They've been extremely supportive of everything." Another said, "Family members... do try very hard to integrate [me] back in, to kind of give me a little bit of leeway if I would say something wrong or do something that's out of the norm. And so, because of that, it made things a little bit easier."

For some veterans who returned to live with parents, living together provided an opening for honest communication about experiences during deployment. One veteran spoke about how since his return he and his father, a police officer, had enjoyed more open conversations: "Since I [went] to Iraq, [my dad] has been much more open about speaking about his experiences as a cop... As a child I didn't interact with him about stuff like that... he didn't ever want to talk about it. I guess once I had ... credibility then I had something to relate to him. I could talk about Iraq and he could relate it to experiences he's had as a police officer." This illustrates how, within family systems theory, family members can recognize adult children's increasing maturity and autonomy while maintaining or even expanding emotional connectedness, thus contributing to differentiation in the relationship (Carter and McGoldrick 2005a). As Skowron (2009) describes, in a well-functioning family system, increased autonomy, when authentically recognized by other members of the family unit, can promote intimacy. 
In another case, even when parents were able to recognize changes in their adult veteran child, the veteran felt that his parents' inability to relate to his experience of warfare impeded their understanding and connection. He explained, "I realized that it's not until you've gone through [war] that you really, fully understand what it is. I can tell stories all night long and [my parents] probably won't really grasp what's going on. They may not care as much... because I'm here and safe.... That was just one little portion of their lives, versus that was everything there was for me that year." This young man felt supported by his parents, while also recognizing their limitations. His lack of emotional reactivity to these limitations suggests a well-differentiated self (Skowron 2009).

Overall, veterans appreciated when their parents' attempted to create emotional connectedness. In some situations, veterans and their parents become emotionally closer through sharing of experiences. This was most often the case in families where other members had experiences in the military or uniformed services.

For other veterans, emotional distance remained. In this small sample of participants, emotional distance post-separation from the military fit within a premilitary family dynamic that discouraged emotional communication and openness.

Problems redefining family roles

Several veterans spoke about conflict emerging with their parents as they tried to redefine their roles in the family. This seemed to be particularly challenging for younger veterans. This finding is expected as these veterans likely had less experience with differentiation prior to leaving the family to join the military or to be deployed.

Veterans who had initially moved out of their parents' home to join the military reported that their parents sometimes treated them like the teenager who had left, not the young adult who returned. One veteran described the situation this way: "I moved home because [my fiancé and I] needed to save money. And it was difficult living at home after you've been in the Marines.... you know, you've been gone for a long time, done a lot of things. Then you go home and it's like... how do I put it? I would recommend that veterans not live at home if they could.... Getting treated the same as you did before you were a Marine... It just 
creates anger." Another veteran reported: "Sometimes they kind of treat me like I'm the same kid that left after high school. My mom will give me a curfew or something. [But] I'm really 22 years old. Don't treat me like a kid." In these families, the parents were unable to witness their adult child's maturation. Instead of recognizing the child's new identity, veteran children and their parents slipped back into preexisting patterns of relating. The veteran children felt their growth invalidated and often positioned themselves antagonistically towards their parents, setting the stage for future cut-off.

Another pattern that emerged for young veterans returning home was that parents observed the veteran child's maturation and shifted their expectations of the child in a way that felt to the veteran as placing too much responsibility on him, again failing to recognize the veteran for who he felt himself to have become. One young man shared: My parents are "depending on me for everything. I pretty much have to do everything to hold the family together." He went on: "They think I should know more [than I do] or be really good at things.... It's like they think [I'm] superman." While parents rely on adult children for emotional support, the process of differentiation can be constrained (Blacker 2005).

The most harmonious relationships were reported by veterans who felt that their parents recognized the changes they had gone through while serving in the military and gave them space, offering a supportive presence by asking solicitous questions but recognizing that the veteran child needed time to adjust to civilian life. Relationships were strained when parents treated veterans as children who needed to be protected, or as adults who should immediately take on important family responsibilities that the veteran child perceived as too demanding.

Family members support veteran children through transition A number of veterans described difficulties adjusting to civilian life. Parents often were the first to become aware of these difficulties, some of which reflected personality or behavioral changes, while others involved more serious psychiatric problems. Parents were concerned about the changes they witnessed in their adult children when the separated from the military.

One veteran who lived with his father for a year after separating recalled: "My dad said I used to be a happy, go-lucky person. I'm not an unhappy person, 
but [he said], 'You're more serious. You're not a jokey kind of person

[anymore]." Another veteran who lived with his parents recounted, "Once I came back I just went back to school and I didn't take any counseling to stabilize.... It was hard to be yourself again. I think I became more isolated from... my family... They all support me. But you can feel that you're not the same... My Mom was worried, because she was like, 'What's wrong with you? Are you okay?"”

When veterans experienced normal transition stress, like in the examples above, adult veteran children appreciated parental solicitousness while also benefiting from space and time to adapt to civilian life and recover from the strain of military service. Parents maintained emotional connection with their veteran children by not forcing them to inhabit prior roles, communicating directly about the changes they observed, and giving the veteran the opportunity to settle into a new sense of self after separation from the military.

In circumstances where veterans returned home with PTSD, the family unit experienced far greater stress. A veteran who returned home with undiagnosed PTSD spoke about how he had turned to drugs to cope with his paranoia, ended up homeless, and after nearly attempting suicide was placed on a psychiatric hold at a hospital. "After the three days was up, my mother showed up to the hospital, and she basically begged them to keep me. [She said] that they needed to help me with getting more help, and that I was a veteran and that I'd been having issues, and I ran away from everybody, and she wanted her son back." He recalled, "I know that at certain times I was probably overwhelming, especially to my mom."

Another veteran who reported having PTSD commented, "my family were used to me being this quiet, meek, nice, person. When I came back,...I would have angry outbursts.... [Before my diagnosis] my mom would say to me, 'You know, if I wasn't your mother and I didn't know you, I probably wouldn't even be as loving.' She's like, 'Because I know you, I know this isn't you. I'm putting up with it. I'm enduring you.",

In both these cases, when the veteran child was diagnosed with PTSD, it created a language for communication about the strain in the parent-child relationship. Undiagnosed problems led parents to feel helpless in the face of their 
child's suffering. While veterans still reported some conflict with parents, getting appropriate care improved the relationship substantially.

Sexual trauma is a particular problem for women veterans and their families Many women veterans experience sexual trauma while in the military, which often complicates their readjustment to civilian life (Kimerling et al. 2010). Both of the women veterans who lived with their parents after separation had been sexually assaulted during their service. (Three of the seven women in the full sample reported being sexually assaulted during their military service.) One female veteran described how hard it was to maintain her independence while living with her parents. She reported that her mother had wanted her to return home immediately after she separated because of the sexual assault: "[My mother] wanted me to be her baby, just come home, let me take care of you kind of thing." In spite of her mother's desire, she stayed where she had been stationed for six months before returning to California: "I didn't want to uproot myself just yet.... [I didn't want to] become dependent again. And, that's exactly what happened." After returning home, she said, her independence "all went away. That's probably why I so quickly jumped into school when I wasn't ready. I should have taken more time off. I just didn't want to be home."

In this instance, the veteran experienced her mother's support as hindering her ability to grow autonomously. Despite having been assaulted, she felt that she had grown and benefitted from her time in the service. Her mother, distressed by the assault, was unable to recognize the positive ways that her daughter had changed. Thus, they were unable to have an authentic relationship and the mother's attempts to increase emotional connection were rebuffed by the veteran child who felt that she was having her autonomy diminished.

The other woman veteran who had been assaulted when in the military said that her parents had been "extremely supportive" as she went through a legal struggle within the military after reporting the rape. After she separated from the military, she lived with an abusive, alcoholic boyfriend and then moved in with her parents after that relationship ended. While living with her parents, she was able to focus on getting appropriate care to help heal from the assault and its aftermath. 


\section{DISCUSSION}

Almost three-quarters of the veterans 25 years or younger, and a third of veterans age 26 - 31 lived with their parents at some point after they separated from the military. In some cases they lived with their parents for an extended period of time; in other instances, they only lived with parents for a short period before moving out to work or attend school. These household arrangements are consistent with a trend in the general population of young people returning to live with their parents after living independently (Mitchell 2006; Settersten and Ray 2010). Indeed, almost $60 \%$ of young adults return home to live with parents for at least some period of time after leaving the family home (Atwood and Scholtz 2008). While in this way, the phenomenon of young adult children returning home is normative in our society, the particular transition that young adult veterans navigate when they separate from the military is vastly more complex than the transition non-veteran youth go through, as veterans are not merely reentering the family home, but are leaving the structure and demands of the military. In addition, most veterans who have served in Afghanistan and Iraq have experienced combat and often have been exposed to traumatic stressors; more than a quarter return from deployment with PTSD (Sayer et al. 2010).

Most veterans who lived with their parents reported positive experiences, sharing that parents provided both instrumental and emotional support. This is similar to findings in the general population. In contrast to popular media portrayals that imply that adult children and their parents find communal living odious (e.g. Davidson 2011; McCarthy 2010; Morello and Mellnik 2011), studies show the vast majority of adult children and their parents who live together report high satisfaction levels and that only a small proportion of families report significant conflict or stress (Mitchell 2006). These intergenerational living arrangements are characterized by mutual interdependence and reciprocity; while adult children experience instrumental and financial support, parents report enjoying companionship and experiencing fulfillment in supporting their children (Mitchell 2006). These reports from the general population and veterans in this study are consistent with family systems theory, suggesting that members of a family system can evolve a new balance of autonomy, support, and connection, and recognize shifting roles and identities even when a young adult lives at home (Bowen 1966; Carter and McGoldrick 2005b; Skowron 2009). 
While parental support was appreciated, for some veterans, conflict arose in relationships with parents as parents learned about their adult children, veterans readjusted to civilian life, and families adjusted to new family roles. Veterans particularly disliked being treated as though they were children or had never been in the military. This was especially a problem for younger veterans, who were more likely to have left home for the first time to join the military. For these veterans, the process of differentiation seems to have been interrupted: parents maintained an image of their past relationship with their child and reacted to their adult children as such, while veteran children responded to unresolved emotional issues with their parents and were unable to form adult-adult relationships with their parents (Blacker 2005; Carter and McGoldrick 2005a).

According to family systems theory, anxiety and distress can arise as families realign their roles and redefine relationships, especially in the context of an external stressor, such as when the veteran returns from war with mental health problems or has difficulty finding employment (McGoldrick and Carter 2005). Indeed, demonstrating the importance of the family unit to the veteran's continued health, parents were often the first to notice mental health and adjustment problems when their adult veteran children returned home. In some cases, parents participated actively to get appropriate care for their adult children.

Our findings indicate that the process of parent-adult child readjustment within the family of origin is similar to the process of adjustment of marital couples when one spouse returns from military service (Bowling and Sherman 2008; Faber et al. 2008; Hutchinson and Banks-Williams 2006; Lapp et al. 2010; Makin-Byrd et al. 2011; Sayers et al. 2009; Tanielian and Jaycox 2008). Veterans and their spouses report difficulties with dividing household responsibilities and becoming reacquainted. Many veterans describe feeling like a stranger in their own home. Similarly, while veterans enjoyed spending time with their parents, both they and their parents went through a challenging adjustment as they figured out how to relate to one another.

Distinct from the problems that marital couples face, there were a number of cases where veterans living with their parents felt as though they were treated like a child, not someone who had been to war and back. This struggle to create a new family dynamic that recognizes the maturation that the adult veteran child has experienced while serving in the military was also reported in Faber's (2008) 
study of reservists and their parents. Although having a young adult veteran child return home caused a strain on families, we found that similar to families coping with loss, most families were resilient to this strain, demonstrating an ability to rebound from the challenges of deployment and return (Walsh 1996).

Nevertheless, there were situations in which conflict with parents led veterans to move into school, a relationship, or work with undue haste. According to family systems theory, when developmental tasks such as differentiation are not resolved in the appropriate life cycle stage, emotional issues may linger and act as burdens on future transitions and relationships (Carter and McGoldrick 2005b).

There were few noticeable gender differences within our sample in terms of the experiences that veterans had living with their parents. However, the fact that both of the women veterans who lived with their parents had experienced sexual assault means that it is difficult to untangle their experiences of living with their parents from their experiences of their parents response to their assaults. The women perceived their parents responses to the assaults very differently: while one woman found her parents support very helpful and had moved in with her parents in order to benefit from their care, the other woman had not wanted to live with her parents and reported increased conflict with her mother because of her mother's response to her assault.

When men or women veterans with PTSD returned to live with parents, the situation was much more difficult. This is similar to literature that shows that couples where a veteran returns with PTSD have higher rates of marital distress (Hayes et al. 2010; Renshaw et al. 2008).

Implications for clinicians and programs

Programs that work with military families are designed primarily for spouses and children of service members, not parents (Fleet and Family Support Center 2011; National Military Family Association 2011; US Marine Corps Family Life 2011); yet parents of returning veterans need information and support as they welcome home their adult children who have served in the military. Relationships with parents remain critical throughout young adulthood, and indeed over the entire life cycle (McGoldrick and Carter 2005). While some parents may find support from grass roots groups like Blue Star Mothers (http://www.bluestarmothers.org/), there are few programs nationwide for parents of returning veterans. Since many 
veterans live with their parents immediately after separation, parents should be educated about what the veteran is likely to be experiencing and how to best support the veteran. In cases where a veteran has adjustment difficulties or a mental health problem, parents need additional support to understand what is happening and to help their adult child navigate to appropriate care. Parents should be briefed about normal combat stress reactions and symptoms of PTSD so that they can identify when a veteran requires medical attention.

We recommend that programs working with veterans and their parents use a family resilience model (Walsh 1998), which developed from family systems theory and focuses interventions on families' strengths and resources. In this model, family members are encouraged to collaborate to build new competencies and develop mutual support. Clinicians can work with families to develop flexibility, maintain connectedness, and harness social and economic resources in the face of difficulties made apparent by the adult veteran child's homecoming. Clinicians may find families benefit from introducing the concept of differentiation and including examples of specific issues that are likely to arise when adult children veterans return to live with their family of origin, role playing how these issues might be handled productively.

Limitations and implications for future research

The findings of the present study are not necessarily generalizable to all veterans. The study was small and did not seek to be representative of all veterans. Additionally, the study only explored the relationship between veterans and their parents from the perspective of the veteran. In order to better understand the experience of veterans and their families when living together after separation from the military, future research should follow veterans and their parents longitudinally in order to assess trajectories of support and conflict as both groups adjust to post-military life together. Future research on reintegration of veterans should consider not just conjugal families, but veterans' families of origin.

\section{CONCLUSION}

To our knowledge, this is the first study to examine the experiences of veterans living with their parents after separation from the military. Research on the experiences of veterans and their families has overwhelmingly focused on 
veterans' spouses and children. We found that many veterans, especially young veterans, live with their parents for a period of weeks to years. While veterans found parents supportive and helpful, they also described conflict arising within the family. Most young adult veteran children were able to continue their process of differentiation while living with their parents.

Despite the critical role that families of origin play in the lives of their adult veteran children, research on veteran families and programming to support reintegration ignores veterans' parents. This likely represents an enduring bias against sustaining intimate contact with parents in western culture. We hope this research spurs programming to help veterans and their parents in the critical transition period as parents strive to provide much needed support to their adult children who are returning veterans.

\section{References}

atlas.ti (2011). http://www.atlasti.com/.

Atwood, J. D., \& Scholtz, C. (2008). The Quarter-life Time Period: An Age of Indulgence, Crisis or Both? Contemporary Family Therapy, 30(4), 233-250. Berkman, L., \& Glass, T. (2000). Social integration, social networks, social support and health. In L. Berkman, \& I. Kawachi (Eds.), Social Epidemiology (pp. 137-173). New York: Oxford University Press.

Blacker, L. (2005). The Launching Phase of the Life Cycle. In B. Carter, \& M. McGoldrick (Eds.), The Expanded Family Life Cycle: Invidual, Family, and Social Perspectives (pp. 287-306). Boston, MA: Allyn \& Bacon.

Bowen, M. (1966). The use of family theory in clinical practice. Comprehensive Psychiatry, 7(5), 345-374.

Bowen, M. (1974). Alcoholism as viewed through family systems theory and family psychotherapy. Annals of the New York Academy of Sciences, 233, 115122.

Bowling, U. B., \& Sherman, M. D. (2008). Welcoming them home: Supporting service members and their families in navigating the tasks of reintegration.

Professional Psychology: Research and Practice, 39(4), 451-458, doi:10.1037/0735-7028.39.4.451.

Bronfenbrenner, U. (1979). The Ecology of Human Development: Experiments by Nature and Design. Cambridge, MA: Harvard University Press. 
Carter, B., \& McGoldrick, M. (2005a). Coaching at Various Stages of the Life Cycle. In B. Carter, \& M. McGoldrick (Eds.), The Expanded Family Life Cycle: Invidual, Family, and Social Perspectives (pp. 436-454). Boston, MA: Allyn \& Bacon.

Carter, B., \& McGoldrick, M. (2005b). Overview: The Expanded Family Life Cycle: Individual, Family, and Social Perspectives. In B. Carter, \& M. McGoldrick (Eds.), The Expanded Family Life Cycle: Invidual, Family, and Social Perspectives (pp. 1-26). Boston, MA: Allyn \& Bacon.

Chandra, A., Burns, R., \& Tanielian, T. (2008). Understanding the impact of deployment on children and families: findings from a pilot study of Operation Purple Camp participants. In RAND (Ed.). Santa Monica, CA: RAND. CHIS (2011). California Health Interview Survey (CHIS). http://www.chis.ucla.edu/.

Crow, J. R., \& Myers-Bowman, K. S. (2011). "A Fear Like I've Never Felt": Experiences of Parents Whose Adult Children Deployed to Combat Zones. Marriage and Family Review, 47(3), 164-195.

Davidson, L. (2011). Retirement Is Blocked By The Revolving Door. http://www.forbes.com/sites/financialfinesse/2011/08/04/retirement-is-blockedby-the-revolving-door/. Accessed Sept 072011.

Demers, A. (2009). The War at Home: Consequences of Loving a Veteran of the Iraq and Afghanistan Wars. The Internet Journal of Mental Health, 6(1).

Faber, A. J., Willerton, E., Clymer, S. R., MacDermid, S. M., \& Weiss, H. M. (2008). Ambiguous absence, ambiguous presence: a qualitative study of military reserve families in wartime. J Fam Psychol, 22(2), 222-230, doi:2008-03770-005 [pii]

10.1037/0893-3200.22.2.222 [doi].

Fleet and Family Support Center (2011).

http://www.military.com/benefits/resources/family-support/fleet-and-familysupport-center.

Fulmer, R. (2005). Becoming an Adult: Leaving Home and Staying Connected. In B. Carter, \& M. McGoldrick (Eds.), The Expanded Family Life Cycle: Invidual, Family, and Social Perspectives (pp. 215-230). Boston, MA: Allyn \& Bacon.

Hayes, J., Wakefield, B., Andresen, E. M., Scherrer, J., Traylor, L., Wiegmann, P., et al. (2010). Identification of domains and measures for assessment battery to 
examine well-being of spouses of OIF/OEF veterans with PTSD. J Rehabil Res Dev, 47(9), 825-840.

Hollingsworth, W. G. (2011). Community Family Therapy with Military Families Experiencing Deployment. Contemporary Family Therapy, 33(3), 215-228.

House, J. S. (1981). Work stress and social support. Reading, MA: AddisonWesley.

Hutchinson, J., \& Banks-Williams, L. (2006). Clinical Issues and Treatment Considerations for New Veterans: Soldiers of the Wars in Iraq and Afghanistan. Primary Psychiatry, 13(3), 66-71.

Institute of Medicine (2010). Returning Home from Iraq and Afghanistan: Preliminary Assessment of Readjustment Needs of Veterans, Service Members, and Their Families. Washington, DC: The National Academies Press.

Karney, B. R., Ramchand, R., Osilla, K. C., Caldarone, L. B., \& Burns, R. M. (2008). Invisible Wounds: Predicting the Immediate and Long-Term Consequences of Mental Health Problems in Veterans of Operation Enduring Freedom and Operation Iraqi Freedom. Santa Monica, CA: RAND.

Kimerling, R., Street, A., Pavao, J., Smith, M., Cronkite, R., Holmes, T., et al. (2010). Military-Related Sexual Trauma Among Veterans Health Administration Patients Returning From Iraq and Afghanistan. American Journal of Public Health, 100(8), 1409-1412.

Lapp, C. A., Taft, L. B., Tollefson, T., Hoepner, A., Moore, K., \& Divyak, K. (2010). Stress and coping on the home front: guard and reserve spouses searching for a new normal. J Fam Nurs, 16(1), 45-67, doi:1074840709357347 [pii] 10.1177/1074840709357347 [doi].

Lester, P., Peterson, K., Reeves, J., Knauss, L., Glover, D., Mogil, C., et al. (2010). The long war and parental combat deployment: effects on military children and at-home spouses. J Am Acad Child Adolesc Psychiatry, 49(4), 310320, doi:00004583-201004000-00006 [pii].

Makin-Byrd, K., Gifford, E., McCutcheon, S., \& Glynn, S. (2011). Family and couples treatment for newly returning veterans. Professional Psychology: Research and Practice, 42(1), 47-55.

Mansfield, A. J., Kaufman, J. S., Engel, C. C., \& Gaynes, B. N. (2011).

Deployment and Mental Health Diagnoses Among Children of US Army Personnel. Arch Pediatr Adolesc Med, doi:archpediatrics.2011.123 [pii] 
10.1001/archpediatrics.2011.123 [doi].

McCarthy, R. (2010). Number of Adult Americans Living With Their Parents Has Exploded. http://www.huffingtonpost.com/2010/12/10/number-of-adultamericans-living-with-their-parents_n_795185.html. Accessed Sept 072011. McFarlane, A. C. (2009). Military deployment: the impact on children and family adjustment and the need for care. Curr Opin Psychiatry, 22(4), 369-373, doi:10.1097/YCO.0b013e32832c9064 [doi].

McGoldrick, M., \& Carter, B. (2005). Self in Context: The Individual Life Cycle in Systemic Perspective. In B. Carter, \& M. McGoldrick (Eds.), The Expanded Family Life Cycle: Invidual, Family, and Social Perspectives (pp. 27-46). Boston, MA: Allyn \& Bacon.

Mitchell, B. (2006). The boomerang age: Transitions to adulthood in families. New Brunswick, NJ: AldineTransaction.

Morello, C., \& Mellnik, T. (2011). Recession pushes more in D.C. area to live with relatives. http://www.washingtonpost.com/local/recession-pushes-more-indc-area-to-live-with-relatives/2011/08/17/gIQANHTaMJ_story.html. Accessed Sept 072011.

National Military Family Association (2011).

http://www.militaryfamily.org/2011.

Renshaw, K. D., Rodrigues, C. S., \& Jones, D. H. (2008). Psychological symptoms and marital satisfaction in spouses of Operation Iraqi Freedom veterans: relationships with spouses' perceptions of veterans' experiences and symptoms. J Fam Psychol, 22(4), 586-594, doi:2008-10898-010 [pii] 10.1037/0893-3200.22.3.586 [doi].

Rosen, E. J. (2005). Men in Transition: The "New Man". In B. Carter, \& M. McGoldrick (Eds.), The Expanded Family Life Cycle: Invidual, Family, and Social Perspectives (pp. 124-140). Boston, MA: Allyn \& Bacon.

Sahin, Z. S., Nalbone, D. P., Wetchler, J. L., \& Bercik, J. M. (2010). The Relationship of Differentiation, Family Coping Skills, and Family Functioning with Optimism in College-Age Students. Contemporary Family Therapy, 32(3), 238-256.

Sayer, N. A., Friedemann-Sanchez, G., Spoont, M., Murdoch, M., Parker, L. E., Chiros, C., et al. (2009). A qualitative study of determinants of PTSD treatment 
initiation in veterans. Psychiatry, 72(3), 238-255, doi:10.1521/psyc.2009.72.3.238 [doi] 10.1521/psyc.2009.72.3.238 [pii].

Sayer, N., Noorbaloochi, S., Frazier, P., Carlson, K., Gravely, A., \& Murdoch, M. (2010). Reintegration problems and treatment interests among Iraq and Afghanistan combat veterans receiving VA medical care. Psychiatric Services, 61(6), 589-597.

Sayers, S. L., Farrow, V. A., Ross, J., \& Oslin, D. W. (2009). Family problems among recently returned military veterans referred for a mental health evaluation. J Clin Psychiatry, 70(2), 163-170, doi:ej07m03863 [pii].

Settersten, R. A., Jr., \& Ray, B. (2010). What's going on with young people today? the long and twisting path to adulthood. Future Child, 20(1), 19-41. Sheon, N. (2007). Overview of Atlas.ti 5.2.

Skowron, E. A., Stanley, K. L., \& Shapiro, M. D. (2009). A Longitudinal Perspective on Differentiation of Self, Interpersonal and Psychological WellBeing in Young Adulthood. Contemporary Family Therapy, 31(1), 3-18.

Tanielian, T., \& Jaycox, L. (2008). Invisible Wounds of War: Psychological and Cognitive Injuries, Their Consequences, and Services to Assist Recovery. Santa Monica, CA: RAND Corporation.

US Marine Corps Family Life (2011). http://www.usmc-mccs.org/family/ Walsh, F. (1996). Family Resiliance: A Concept and Its Application. Family Process, 35, 261-281.

Walsh, F. (1998). Strengthening Family Resilience. New York: The Guilford Press.

Table 1: Living Situation After Separation

\begin{tabular}{|l|l|l|l|l|r|}
\hline & Parents & Spouse/Partner & Roommates/Alone & Other & TOTAL \\
\hline $\begin{array}{l}\text { Age 22 - } \\
25\end{array}$ & $8(73 \%)$ & $3(27 \%)$ & - & - & 11 \\
\hline $\begin{array}{l}\text { Age 26- } \\
31\end{array}$ & $3 *(37 \%)$ & $3 *(37 \%)$ & $3(37 \%)$ & - & 8 \\
\hline $\begin{array}{l}\text { Age } 32- \\
52\end{array}$ & - & $3(60 \%)$ & $1(20 \%)$ & $1(20 \%)$ & 5 \\
\hline
\end{tabular}


* one participant lived with his parents together with his wife and children

Table 2. Demographic Characteristics of Veterans Who Lived with Parents

\begin{tabular}{|c|c|c|}
\hline & $\mathrm{N}$ & $\%$ \\
\hline Total & 11 & 100.0 \\
\hline \multicolumn{3}{|l|}{ Age in years } \\
\hline $18-24$ & 3 & 27.3 \\
\hline $25-30$ & 6 & 54.5 \\
\hline $31-34$ & 2 & 18.2 \\
\hline \multicolumn{3}{|l|}{ Race } \\
\hline White & 3 & 27.3 \\
\hline African American & 1 & 9.0 \\
\hline Asian & 2 & 18.2 \\
\hline Hispanic & 2 & 18.2 \\
\hline Unknown & 3 & 27.3 \\
\hline \multicolumn{3}{|l|}{ Sex } \\
\hline Male & 9 & 81.8 \\
\hline Female & 2 & 18.2 \\
\hline \multicolumn{3}{|l|}{ Military Branch } \\
\hline Air Force & 2 & 18.2 \\
\hline Army & 3 & 27.3 \\
\hline Army Reserves & 1 & 9.0 \\
\hline Marines & 3 & 27.3 \\
\hline Navy & 2 & 18.2 \\
\hline \multicolumn{2}{|c|}{$\begin{array}{l}\text { Years Since Separation from } \\
\text { Military }\end{array}$} & \\
\hline$<1$ & 2 & 18.2 \\
\hline $1-2$ & 3 & 27.3 \\
\hline $2-3$ & 4 & 36.4 \\
\hline$>4$ & 2 & 18.2 \\
\hline
\end{tabular}


